\title{
MARKETING DE RELACIONAMENTO E INOVAÇÃO: UM ESTUDO EM ORGANIZAÇÕES DO SEGMENTO GRÁFICO EM NATAL/RN
}

ROSA, Ana Débora Morais da. Agente Local de Inovação pelo SEBRAE-RN 2012-2013. Bolsista do CNPQ. Formada em Administração de Empresas pela Universidade Federal do Rio Grande do Norte - UFRN (2010). Cursando pós-graduação em Gestão Estratégica de Pessoas pela UNI-RN, Rua Teatrólogo Meira Pires, 1993 CEP 59.080-090, Natal/RN. Brasil. Email: anadeboramorais@ yahoo.com.br.

ARAÚJO, Richard Medeiros de. Doutor em Administração pelo PPGA/UFRN. Professor da UNIFACEX. Orientador do ALI/RN. E-mail: richardmaraujo@uol.com.br.

\section{Resumo}

Este trabalho busca analisar, por meio de uma pesquisa quantitativa, realizada através da aplicaçãode questionários com perguntas fechadas, o uso da dimensão Relacionamento, uma das 13 dimensões que compõemo instrumento Radar da Inovação, método utilizado para mensurar o grau de inovação das empresas. As empresas analisadas, em sua totalidade sete gráficas atendidas pelo Programa Agentes Locais de Inovação do Rio Grande do Norte, não possuem ações eficazes para manter os clientes, conhecem suas necessidades e expectativas com relação ao produto/serviço, contudo não inovaram em práticas para aperfeiçoar e firmar relacionamentos duradouros. Foi possível perceber que os empresários estão absorvendo aos poucos essa cultura de propiciar facilidades e recursos que atendam aos desejos e necessidades dos seus clientes. Conclui-se que as empresas estão abertas a novos conhecimentos, conceitos e mudanças, facilitando o incentivo à cultura da inovação e a novas abordagens que propiciem o crescimento e expansão do setor, por meio de práticas para melhorar o relacionamento com os clientes.

Palavras-chave: Radar da Inovação, Dimensão Relacionamento, Relacionamento, Empresas gráficas, Rio Grande do Norte.

\section{RELATIONSHIP AND INNOVATION MARKETING: A STUDY OF GRAPHIC SEGMENT ORGANIZATIONS IN NATAL-RN}

\begin{abstract}
This work aims to analyze, through a quantitative research with the application of questionnaires with closed questions, the use of the Relationship dimension, one of the 13 dimensions that make up the Innovation Radar instrument, a method applied to measure the degree of innovation of enterprises. The analyzed companies, as a whole, seven graphics assisted by the Innovation Local Agents Program at Rio Grande do Norte, don't have effective actions to keep the customers, they know their needs and expectations about the product / service, but, despite that, they haven't innovated their practices to improve and establish lasting relationships. It was possible to notice that entrepreneurs are slowly absorbing the culture of providing facilities and resourcesthat meet the desires and needs of their customers. We conclude that companies are open to new knowledge, concepts and changes, which is a cultural incentive for innovation and new approaches that will propitiate the growth and the expansion of the sector, using practices to improve the relationship with their customers.
\end{abstract}

KeYwords: Innovation Radar, Relationship Dimension, Relationship, Graphic Companies, Rio Grande do Norte. 


\section{INTRODUÇÃo}

Atualmente, muito se tem discutido acerca da inovação como umelemento competitivo, um diferencial entre as organizações. A inovação propicia a expansão de empresas responsáveis por mudanças em suas práticas de gestão, processos, produtos, marketing, entre outras áreas.

A busca e a prática da inovação passam a ser uma necessidade imprescindível para que as organizações possam encontrar os mecanismos mais adequados para conduzir as suas operações e, principalmente, formular e implementar suas estratégias (CÂNDIDO; BRITO, 2003). "A inovação não acontece por acidente. É resultado de um processo sistemático e organizado de mudança administrada, que transforma novas ideias em realidades de sucesso" (BESSANT; TIDD, 2009, p.45).

As empresas estão se preocupando em dar atenção exclusiva ao seu cliente, pois a organização, para crescer e ter estabilidade, necessita adotar uma política de marketing de relacionamento. É de grande importância alcançar a satisfação total de seus clientes. O marketing de relacionamento permite que a empresa projete todas as suas ações, buscando uma aproximação e uma maior integração entre o cliente e a empresa. Se a empresa se preocupa com o bemestar e a satisfação do seu cliente, consegue atender prontamente suas solicitações. Ele certamente reconhecerá o valor e esforço disponibilizado e, possivelmente, se tornará fiel à organização.

A satisfação do consumidor é primordial para a prosperidade e permanência das empresas no mercado competitivo. Clientes satisfeitos são fiéis, para eles o preço não é o principal atrativo. Bee (2000) enfatiza a importância da boa comunicação nos relacionamentos, uma vez que a habilidade em se comunicar é a essência do atendimento e fundamental no contato direto com o cliente. É necessário criar uma relação de confiança e parceria.

O presente estudo se propõe a analisar e abordar o tema relacionamento com os clientes, como fator primordial no crescimento e desenvolvimento das organizações, principalmente nas micro e pequenas empresas - MPEs. A dimensão relacionamento, integrante do Diagnóstico Radar da Inovação, será a principal fonte de pesquisa utilizada para a realização do estudo proposto.

Utilizando essa dimensão e analisando os conceitos de marketing de relacionamento, este trabalho tem como objetivo geral propor um relato acerca do comportamento dessa dimensão.

\section{REFERENCIAL TEÓRICO \\ Conceitos de inovação}

Atualmente as MPEs ouvem diariamente a palavra "inovação". Elaestá presente com frequência nas relações internas e externas das organizações. Apalavra inovação vem do latim innovatio, tendo como significado a introdução de alguma novidade, de algo novo, em qualquer atividade humana. O Manual de Oslo (2004), elaborado pela Organização para a Cooperação e o Desenvolvimento econômico-OCDE, na sua terceira edição, define a inovação como a implementação de um produto (bemou serviço), novo ou significativamente melhorado, ou um processo, ou um novo método de marketing, ou um novo método organizacional nas práticas de negócios, na organização do local de trabalho ou nas relações externas.

Segundo o Manual de Oslo (2004), o processo de inovação inclui atividades em várias etapas científicas, tecnológicas, organizacionais, financeiras e comerciais que de fato levem, ou pretendem levar, à implantação de produtos ou processos tecnologicamente novos ou aprimorados. Algumas delas podem ser inovadoras por si mesmas; outras, embora não sejam novidades, são necessárias para a implantação.

"A inovação é a criação de coisas novas ou o
rearranjar de coisas antigas, mas de uma nova
forma. Em termos muito simples, inovar significa
ter uma ideia nova ou, por vezes, aplicar as ideias
de outros com eficácia e, é claro, de forma
original" (SARKAR, 2008, 115-116).

A inovação está em toda parte e é responsável pelo aumento da competitividade no mercado e lucratividade do empresário e da sua equipe de 
colaboradores. Inovar é necessário e primordial no contexto mercadológico, pois é a principal ferramenta da atualidade responsável pelo crescimento e desenvolvimento das organizações. Muitos empresários se questionam se inovar custa caro; contudo, a inovação muitas vezes está relacionada a coisas muito simples. As empresas podem adotar soluções bastante comuns e corriqueiras, mas que fazem a diferença porque são capazes de aumentar a rentabilidade dos empresários, sendo uma forma de diferencial competitivo. Nos dias atuais, uma empresa pode continuar viva no mercado se adaptar e melhorar continuamente seus produtos e serviços para atender às necessidades e proporcionar a satisfação de seus clientes.

Bessant e Tidd (2009) enfatizam que "a inovação realmente faz uma grande diferença para empresas de todos os tipos e tamanhos". É necessário mudar e acompanhar as novas tendências do mercado. Muitas pequenas e médias empresas fracassam por não visualizarem a necessidade de mudar e acompanhar o mercado, esse conhecido pelas suas constantes transformações.

Inovar não é complicado, é simples quando a empresa possui uma forte liderança que estimula um ambiente propício para a criatividade. Desse modo, estrategicamente terá boas condições de inovar. A inovação é a ferramenta específica dos empreendedores, os meios com os quais eles exploram a mudança como uma oportunidade para um negócio diferente ou um serviço diferente (SARKAR, 2008).

\section{Os tipos de inovação}

É fundamental compreender por que as empresas inovam. Uma das principais razões, por exemplo, pode ser entendida pelo aumento da demanda ou pela redução dos custos. Um novo produto, ou processo, pode ser uma fonte de vantagem mercadológica para a organização. A inovação pode melhorar a capacidade empresarial da empresa de adquirir e criar novos conhecimentos, que depois poderão ser usados com a finalidade de desenvolver outras inovações, trazendo benefícios, crescimentos e diferenciação para a empresa.
O Manual de Oslo (2004) ressalta que o trabalho de Joseph Schumpeter influenciou bastante as teorias da inovação. Seu argumento é de que o desenvolvimento econômico é conduzido pela inovação por meio de um processo dinâmico, em que as novas tecnologias substituem as antigas, um processo por ele denominado "destruição criadora". Segundo Schumpeter, inovações "radicais" engendram rupturas mais intensas, enquanto inovações "incrementais" dão continuidade ao processo de mudança. Schumpeter (1934, apud MANUAL DE OSLO, 2004) propôs uma lista de cinco tipos de inovação:

i. Introdução de novos produtos.

ii. Introdução de novos métodos de produção.

iii. Abertura de novos mercados.

iv. Desenvolvimento de novas fontes provedoras de matérias-primas e outros insumos.

v. Criação de novas estruturas de mercado em uma indústria.

A inovação pode ser caracterizada como radical ou incremental. Segundo Sarkar (2008, p.139), "a inovação radical continua a ser no sentido de Schumpeter, algo que é totalmente novo, de acordo com as cinco linhas definidas por esse economista austríaco". Portanto, quando as novas ideias resultam em produtos ou processos totalmente novos, que antes não existiam no mercado. De acordo com Sarkar (2008), inovação incremental geralmente está relacionada com melhorias passo a passo dos produtos existentes e tende a reforçar a posição de mercado.

É importante ressaltar que a organização que inova, oferece produtos e serviços que são úteis aos clientes, utiliza processos mais eficientes, é aberta a novos métodos organizacionais e investe em ações de marketing. Existem diferentes formas de inovação, e elas podem ser classificadas de diversas maneiras.

\section{Radar da inovação}

Em razão do crescimento das práticas inovadoras e da importância socioeconômica da MPE no país, são necessários conhecimento e dados aprofundados da realidade dessas organizações, que busquem diagnosticar e mensurar o atual Grau de Inovação. 
De acordo com o Serviço Brasileiro de Apoio às Micro e Pequenas Empresas - SEBRAE (2010), uma metodologia para mensurar o Grau de Inovação nas empresas foi desenvolvida utilizando como referência o trabalho do professor Mohanbir Sawhney, da Kellogg School of Management, que relaciona as dimensões pelas quais uma empresa pode procurar caminhos para inovar. O Radar da Inovação do professor Sawhney reúne 12 dimensões, entretanto a abordagem não destaca o ambiente interno da organização. Assim, foi desenvolvida pela Bachmann \& Associados (2008) uma dimensão adicional denominada "Ambiência inovadora", já que um clima organizacional propício à inovação é prérequisito para uma empresa inovadora.

Para esta ferramenta, foi adotada uma escala de medição com três situações, variando de 1 a 5 , onde o escore mínimo consiste em uma organização pouco ou nada inovadora, e o escore máximo, em uma organização inovadora sistêmica. Essa avaliação não consiste apenas em avaliar o número de inovações das empresas, mas também a maturidade dos processos de inovação. Pois muitas novas organizações provêm de uma única ideia de sucesso, portanto se entende que isso não é suficiente para caracterizar uma empresa inovadora. Tendo em vista essa questão, foi buscada inspiração em diversos modelos usados para medir o grau de maturidade de processos, optando-se por dar um escore maior às empresas que tenham uma prática estruturada que vise à inovação. Amedição caracteriza as empresas em "pouco ou nada inovadoras", "inovadoras ocasionais" e "inovadoras sistêmicas". Essa escala também atende à recomendação do Manual de Oslo [6], que estabelece que os pontos de vista das empresas sejam registrados, ou em bases binárias, ou com uma estreita faixa de respostas possíveis.

Como período de tempo necessário a ser considerado na avaliação, para acompanhar a evolução da empresa e baseado em várias pesquisas e estudos na área, a metodologia tomou um horizonte de três anos para o levantamento dos dados e informações.

As dimensões utilizadas para avaliar e diagnosticar o atual Grau de Inovação das empresas, fornecendo todos os dados e informações necessárias, podem ser caracterizadas como: Oferta, Plataforma, Marca, Clientes, Soluções, Relacionamento, Agregação de valor, Processos, Organização, Cadeia de fornecimento, Presença, Rede e Ambiência inovadora. É por meio da análise dos dados fornecidos por essas 13 dimensões que se pode conhecer e desenvolver o ambiente inovador no âmbito interno e externo das organizações.

\section{Radar da Inovação: dimensão Relacionamento}

Com a finalidade de operacionalizar o cálculo do Grau de Inovação das empresas, foi desenvolvido um formulário que priorizou o Radar da Inovação. A metodologia também adota uma abordagem mais qualitativa que quantitativa, para respeitar a menor disponibilidade de informações que é típica das MPEs.

A dimensão Relacionamento, originalmente denominada de "Experiência do Cliente", leva em conta tudo que o consumidor vê, ouve, sente ou experimenta, de algum modo, ao interagir com a empresa em todos os momentos. Como exemplos de ações visando fornecer experiências positivas aos clientes, temos:

Oferecer uma planilha eletrônica que ajude o cliente a selecionar o produto mais adequado?

Uma sala de espera com design mais elaborado?

Um catálogo com recursos visuais diferenciados ou com amostras.

Para avaliar a dimensão Relacionamento, tomaramse as questões:

- A empresa adotou alguma facilidade ou recurso (senhas, cafezinho, vitrine, etc.) para melhorar o relacionamento comos clientes?

- A empresa adotou algum novo recurso de informática (web site, email, CD, etc.) para se relacionar com os clientes (BACHMANN; DESTEFANI, 2008)?

Essas questões são de grande importância para desenvolver o relacionamento das empresas com seus clientes, pois atualmente eles não procuram apenas um bom atendimento, buscam um diferencial. O bom relacionamento é o início de todo o processo de fidelização dos clientes. 


\section{Conceitos de marketing}

O marketing, dentre várias definições, é um conjunto de atividades direcionadas para satisfazer as necessidades e desejos do consumidor. É por meio do marketing que as empresas conquistam e fidelizam seus clientes, por meio da produção de bens e/ou serviços, a escolha do preço adequado, a distribuição eficiente e ágil, a comunicação com o público-alvo, seja por meio de propaganda, promoção em pontos de vendas, sorteios e mala direta.

"O marketing é uma das mais poderosas ferramentas empregadas pelas organizações em sua luta eterna pelo crescimento e sobrevivência" (DALRYMPLE; PARSONS, 2003, p.1). Essa é a essência do conceito de marketing e o precedente para a criação da satisfação do cliente e da lealdade.

Para Kotler (2006), o marketing é o processo de planejar e executar a concepção, a determinação do preço, a promoção e a distribuição de ideias, bens e serviços para criar trocas que satisfaçam metas individuais e organizacionais. É necessário que as empresas procurem conhecer o que seus clientes desejam e ofereçam exatamente o que eles necessitam.

"O objetivo do marketing é conhecer e entender o cliente tão bem que o produto ou o serviço seja adequado a ele e se venda sozinho" (KOTLER, 2006 p. 4). O importante é que se antecipem diante dos seus concorrentes e de forma que seus produtos/ serviços sejam atrativos, possuam um diferencial. Assim, as organizações terão clientes satisfeitos e, consequentemente, fidelizados. De acordo com Kotler (2000), as empresas orientadas para o marketing têm uma preocupação constante com os desejos dos clientes. Quando esses desejos mudam, as empresas procuram evoluir, orientando-se pelo que os clientes querem, buscando formas que possam atendê-los.

No âmbito atual, o conceito de marketing está sempre sendo atualizado, o mercado está sempre mudando e as empresas precisam acompanhar essas mudanças. O marketing tem um importante papel no sucesso das organizações. Elas necessitam ter objetivos definidos, estratégias e ações, pois, se não acompanharem as mudanças, tendem a ficar obsoletas.
As organizações não podem operar centradas nas vendas de produtos, e sim no atendimento às necessidades e expectativas dos clientes. Esse é um dos papéis do marketing, simples teoria, mas que na prática tem uma importância relevante no desenvolvimento das empresas.

\section{Marketing de relacionamento}

O marketing de relacionamento - MRé geralmente descrito como uma abordagem para desenvolver clientes leais de longo prazo e, dessa forma, aumentar a lucratividade. Para Gummesson (2010, p. 22), o marketing de relacionamento é a interação das redes de relacionamentos. Segundo o autor, relacionamentos necessitam que pelo menos duas partes estejam em contato uma com a outra. Uma rede é um conjunto de relacionamentos de muitas partes, o que pode se transformar em modelos extremamente complexos. Sendo assim:
"Adotar o marketing de relacionamento significa, para a empresa, que ela se dedique ao estabelecimento, manutenção e constante melhora de seus relacionamentos com seus clientes - sejam os internos, sejam os externos - com uma finalidade de lucro mútuo, de modo que os objetivos das partes envolvidas sejam atingidos" (FELISONIE; GIANGRANDE (2007, p.10).

Em sua essência, o marketing de relacionamento circunda um novo conceito de cliente, aquele que representa parceria, ou mesmo parte integrante essencial à constituição da empresa prestadora de bens ou serviços, e à sua continuidade bem-sucedida no mundo organizacional contemporâneo. Em resumo, marketing de relacionamento é a construção de uma relação duradoura entre a empresa e o cliente, baseada na confiança e em ganhos mútuos ao longo do tempo. Para que a empresa adquira vantagem competitiva e ganhe destaque junto à concorrência, é imprescindível a administração do relacionamento com o cliente. 


\section{Metodologia}

Nesta etapa do trabalho, será explicada a metodologia utilizada, os procedimentos e critérios adotados para a seleção do método de pesquisa e para a coleta dos dados utilizados. Segundo Malhotra (2005), o processo do modelo de pesquisa começa com a definição do problema em questão. Para realizar uma pesquisa é preciso promover o confronto entre os dados, as evidências, as informações coletadas sobre determinado assunto e o conhecimento teórico acumulado a respeito dele, objetivando obter informações pertinentes à resolução do problema de pesquisa.

Com relação aos meios e $\mathrm{p}$ rocedimentos de pesquisa, o estudo é caracterizado como uma pesquisa bibliográfica e exploratória, com o objetivo de analisar as ações de marketing de relacionamento em empresas participantes do Programa Agentes Locais de Inovação - ALI do segmento gráfico no município de Natal-RN.

De acordo com Vergara (2005, p. 47-48), pesquisa bibliográfica é o estudo sistematizado desenvolvido com base em material publicado em livros, revistas, jornais e redes eletrônicas, isto é, material acessível ao público em geral.

O material utilizado na pesquisa bibliográfica constitui-se de livros, artigos em revistas, anais de congresso, periódicos, internet e outros. Neste estudo, várias obras dessa natureza foram utilizadas como subsídio à elaboração do instrumento de coleta, especificamente os que tratavam dos temas inovação e marketing de relacionamento, bem como o "Radar da Inovação".

$\mathrm{O}$ universo da pesquisa são empresas do setor gráfico do município de Natal-RN, que corresponde a sete organizações. $O$ instrumento de coleta foi aplicado aos gestores das gráficas atendidas pelo ProgramaALI.

A técnica de coleta de dados adotada foi o questionário com perguntas claras e objetivas, o qual, segundo Vergara (2007), "não é apenas um formulário, ou um conjunto de questões listadas sem muita reflexão". Para tanto, requer esforço intelectual anterior de planejamento, com base na conceituação do problema de pesquisa e do plano da pesquisa.

O instrumento de pesquisa é composto por questões objetivas e fechadas, cujas variáveis que o compõem têm por base a dimensão Relacionamento do Radar da Inovação, desenvolvido utilizando como referência o trabalho de Mohanbir Sawhney, da Kellogg School of Management (SEBRAE, 2010).

Os dados coletados possibilitaram informações necessárias para pesquisa. Foi realizado um levantamento e contagem das respostas, o resultado dos dados foi tratado quantitativamente, através da tabulação no software Word e Excel, e serão apresentados por meio de gráficos.

\section{Análise dos dados}

Este capítulo tem por objetivo analisar os dados e resultados da pesquisa de campo, realizada com os gestores de empresas do segmento gráfico do município de Natal-RN. A pesquisa foi aplicada em sete gestores por meio de um questionário comperguntas específicas. As gráficas que constituem o universo da pesquisa não serão identificadas e, sim, chamadas de empresas A, B, C, D, E, F e G.

\section{Perfil das empresas}

$\mathrm{Na}$ pesquisa foram abordadas questões como o tipo da empresa, faturamento anual, idade, sexo e grau de instrução do gestor. Os questionários foram aplicados com gráficas atuantes nos bairros de Cidade Alta, Tirol, Alecrim, Candelária e na Zona Norte do município de Natal.

Setenta e um por cento das empresas entrevistadas possuem o faturamento médio anual de até R\$ $360.000,00$, e $29 \%$ de $\mathrm{R} \$ 360.000,01$ a $\mathrm{R} \$$ 3.600.000,00. As demais opções não foram escolhidas, evidenciando claramente que o setor está inserido na condição de empresas de micro e pequeno portes, foco do trabalho realizado. 
Tabela 1 - Perfil das empresas.

\begin{tabular}{l|ccc|}
\hline Faturamento & R\$ 0,00 a 360.000,00 & $\begin{array}{c}\text { R\$ 360.000,01 a } \\
\mathbf{3 . 6 0 0 . 0 0 0 , 0 0}\end{array}$ & $\begin{array}{c}\text { Acima de } \mathbf{R} \$ \\
\mathbf{3 . 6 0 0 . 0 0 0 , 0 1}\end{array}$ \\
\hline & & & $0 \%$ \\
\hline
\end{tabular}

Fonte: Pesquisa de campo (2012).

Verificou-se que 57\% das empresas entrevistadas se constituem juridicamente como Empresa Individualde Responsabilidade Limitada; as demais (43\%) correspondem a Sociedade Empresarial (Ltda.), como mostra a Tabela 2.

Tabela 2 - Perfil das empresas.

\begin{tabular}{l|cccccc}
\hline $\begin{array}{l}\text { Tipo de } \\
\text { Empresa }\end{array}$ & $\begin{array}{c}\text { Sociedade } \\
\text { Empresarial } \\
\text { (Ltda) }\end{array}$ & $\begin{array}{c}\text { Empreendedor } \\
\text { Individual }\end{array}$ & $\begin{array}{c}\text { Produtor } \\
\text { Rural }\end{array}$ & $\begin{array}{c}\text { Associação/ } \\
\text { Sindicato }\end{array}$ & $\begin{array}{c}\text { Empresa Individual } \\
\text { de Responsabilidade } \\
\text { Limitada }\end{array}$ & $\begin{array}{c}\text { Outras } \\
\text { Organizações } \\
\text { Privadas }\end{array}$ \\
\hline & $43 \%$ & $0 \%$ & $0 \%$ & $0 \%$ & $57 \%$ & $0 \%$
\end{tabular}

Fonte: Pesquisa de campo (2012).

A Tabela 3 representa a faixa etária dos gestores, compreendendo que grande parte possui acima de 50 anos de idade.

Tabela 3 - Perfil das empresas.

\begin{tabular}{l|ccccc|}
\hline Idade & Até 20 anos & $\begin{array}{c}\text { De 21 anos a } \\
\mathbf{3 0} \text { anos }\end{array}$ & $\begin{array}{c}\text { De 31 anos a } \\
\mathbf{4 0} \text { anos }\end{array}$ & $\begin{array}{c}\text { De 41 anos a } \\
\mathbf{5 0} \text { anos }\end{array}$ & $\begin{array}{c}\text { Acima de 50 } \\
\text { anos }\end{array}$ \\
\hline & $0 \%$ & $28 \%$ & $29 \%$ & $0 \%$ & $43 \%$
\end{tabular}

Fonte: Pesquisa de campo (2012).

Somando-se a quantidade de entrevistados, temos em sua totalidade uma amostra de sete pessoas, todas do sexo masculino. Essa informação pode ser observada na Tabela 4. 
Tabela 4 - Perfil das empresas.

\begin{tabular}{l|cc|}
\hline Sexo & Feminino & Masculino \\
\hline & $0 \%$ & $100 \%$
\end{tabular}

Fonte: Pesquisa de campo (2012).

A Tabela 5 observa o grau de instrução dos gestores das gráficas analisadas, indicando que $43 \%$ dos entrevistados têm nível superior completo; outros três empresários possuem ensino médio completo, e apenas um deles superior incompleto, dados estes que indicam que a maioria dos gestores do setor não investe em cursos de graduação.

Tabela 5 - Perfil das empresas.

\begin{tabular}{c|cccccc}
\hline $\begin{array}{c}\text { Grau de } \\
\text { Instrução }\end{array}$ & $\begin{array}{c}\text { Ensino } \\
\text { Fundamental } \\
\text { incompleto }\end{array}$ & $\begin{array}{c}\text { Ensino } \\
\text { Fundamental } \\
\text { completo }\end{array}$ & $\begin{array}{c}\text { Ensino } \\
\text { Médio } \\
\text { incompleto }\end{array}$ & $\begin{array}{c}\text { Ensino } \\
\text { Médio } \\
\text { completo }\end{array}$ & $\begin{array}{c}\text { Superior } \\
\text { incompleto }\end{array}$ & $\begin{array}{c}\text { Superior } \\
\text { completo }\end{array}$ \\
\hline & $0 \%$ & $0 \%$ & $0 \%$ & $43 \%$ & $14 \%$ & $43 \%$ \\
\hline
\end{tabular}

Fonte: Pesquisa de campo (2012).

Análise do Radar da Inovação e suas dimensões

De acordo com pesquisa realizada pelo Sindicato das Indústrias Gráficas do Rio Grande do Norte (2003/ 2011), as mudanças ocorridas nos últimos anos na economia e no mercado tiveram efeitos sobre todos os segmentos empresariais e a indústria gráfica potiguar não passou incólume por elas. Em síntese, o setor sofreu uma evolução considerávele atualmente o Rio Grande do Norte possui um moderno parque gráfico, com condições de realizar dos mais simples aos mais sofisticados serviços. O aumento da modernização e investimentos em novos equipamentos, o número de empresas sindicalizadas, a queda contínua dos talonários de Notas Fiscais, principal fonte de serviço e renda das pequenas gráficas, a informatização, entre outras, foram algumas das principais mudanças evidenciadas nos últimos anos. Ainda segundo o estudo, essa modernização, que proporcionou competitividade e qualidade ao setor, foi fruto de anos de investimentos feitos pelos empresários. Neste estudo também foi possível perceber as principais necessidades relatadas pelas empresas entrevistadas. Modernização de equipamentos, capital de giro, treinamento de mão de obra e aquisição de novos equipamentos foram algumas citadas como prioridade pelas gráficas.

Utilizando a ferramenta Radar da Inovação, será apresentada uma análise geral das 13 dimensões das sete empresas participantes do Programa Agentes Locais de Inovação, por meio do Quadro 1. 


\begin{tabular}{|c|c|c|c|c|c|c|c|c|c|c|c|c|c|c|}
\hline \multirow[b]{2}{*}{ Empresa } & \multicolumn{13}{|c|}{ Dimensão / pontuação do radar } & \multirow[b]{2}{*}{$\begin{array}{l}\text { Grau } \\
\text { Total }\end{array}$} \\
\hline & $\begin{array}{l}\stackrel{\pi}{0} \\
\stackrel{0}{0} \\
0\end{array}$ & 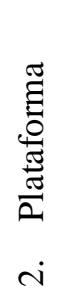 & 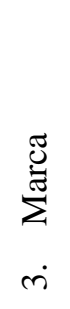 & $\begin{array}{l}\stackrel{0}{0} \\
\stackrel{0}{0} \\
\dot{U} \\
\dot{\sigma}\end{array}$ & 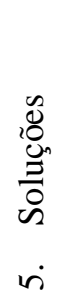 & 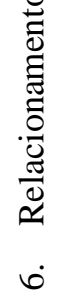 & 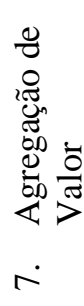 & $\begin{array}{l}\tilde{D} \\
0 \\
0 \\
\delta \\
0 \\
0 \\
0 \\
\infty\end{array}$ & 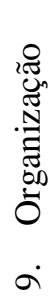 & 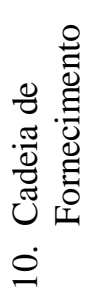 & 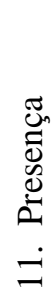 & $\begin{array}{l}\frac{\mathscr{Z}}{0} \\
\simeq \\
\text { ¿ }\end{array}$ & 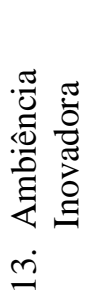 & \\
\hline Empresa A & 3,0 & 4,0 & 3,0 & 3,0 & 2,0 & 1,0 & 1,0 & 1,7 & 1,0 & 1,0 & 1,0 & 1,0 & 2,0 & 2,1 \\
\hline Empresa B & 2,6 & 5,0 & 4,0 & 3,0 & 2,0 & 2,0 & 3,0 & 1,3 & 1,5 & 1,0 & 1,0 & 1,0 & 2,3 & 2,5 \\
\hline Empresa C & 2,2 & 3,0 & 3,0 & 3,0 & $\overline{1,0}$ & 1,0 & 2,0 & 1,7 & 1,0 & 1,0 & 1,0 & 1,0 & 2,0 & 1,9 \\
\hline Empresa D & 2,2 & 4,0 & 5,0 & 3,0 & 3,0 & 4,0 & 2,0 & 1,7 & 2,0 & 1,0 & 1,0 & 1,0 & 2,0 & 2,6 \\
\hline Empresa E & 3,0 & 3,0 & 3,0 & 3,0 & 2,0 & 2,0 & 1,0 & 2,0 & 1,0 & 1,0 & 1,0 & 1,0 & 1,3 & 2,0 \\
\hline Empresa F & 1,8 & 3,0 & 4,0 & 1,7 & $\overline{1,0}$ & 2,0 & 1,0 & 1,3 & 1,0 & 1,0 & 1,0 & 1,0 & 1,5 & 1,8 \\
\hline Empresa G & 3,8 & 3,0 & 5,0 & 3,0 & 3,0 & 3,0 & 5,0 & 1,3 & 3,0 & 1.0 & 3.0 & 1,0 & 3,0 & 3,2 \\
\hline
\end{tabular}

Quadro 1 - Grau de inovação do Radar da Inovação do universo investigado.

Fonte: Dados coletados da Ferramenta Radar da Inovação, aplicado nas empresas em 2012.

Diante da aplicação do Radar da Inovação nas empresas estudadas, foi constatado que, combase nos três últimos anos, as empresas do setor gráfico do município de Natal investiram em novos equipamentos, aumentaram seu mix de produtos e serviços oferecidos aos clientes, identificaram novos mercados, ofertaram novas soluções complementares, entraram nas redes sociais, entre outras mudanças que contribuíram com o desenvolvimento e expansão do setor.

$\mathrm{Na}$ dimensão oferta constatou-se que todas as empresas analisadas lançaram um ou mais de um novo produto no mercado nos últimos três anos, sacolas personalizadas, banners, novos tipos de cartões, convites, entre outros, foram alguns que obtiveram sucesso entre os clientes. Grande parte dessas empresas, quando questionadas se retiraram algum produto por não ter tido uma aceitação muito boa, respondeu que todos os produtos colocados no mercado obtiveram o sucesso esperado. Apenas as empresas A e E retiraram a digitação do seu mix de serviços.

Com relação à dimensão Plataforma, o mesmo produto é oferecido em uma ou mais de duas versões para atingir novos mercados ou grupos de consumidores em todas as empresas. Os empresários estão atentos em oferecer a seus clientes diversas opções e atender a suas necessidades e expectativas.

$\mathrm{Na}$ dimensão Marca, as empresas B, D e G possuem suas marcas registradas. As empresas usam suas marcas em propagandas e utilizam em alguns produtos produzidos, facilitando assim a divulgação do empreendimento sem gerar custos.

Já na dimensão Processos, as empresas adquiriram novos equipamentos para obter maior eficiência, qualidade, flexibilidade ou menor ciclo de produção. Esses dados demonstram que as gráficas estão atentas em oferecer rapidez no processo, qualidade e atendimento rápido aos seus clientes. Além da atenção em novas tecnologias. Com relação aos sistemas de gestão e certificações, os empresários não adotaram nenhuma nova prática de gestão, como o GQT, MEG, Just in Time, Reengenharia, Manual de Boas Práticas e também não receberam qualquer certificação de processo (ISO 9001, ISO 14001 etc.) ou de produto (ABNT).

Com relação à dimensão Organização, a empresa D adotou uma nova abordagem para melhorar seus resultados, como o casual day, política que algumas 
empresas adotam de permitir que os funcionários troquem o visual formal pelo casual uma vez por semana, normalmente no último dia de trabalho. Já a empresa B fez parceria com outra organização para fornecer produtos ou serviços melhores e mais completos. As demais empresas não adotaram nenhuma das práticas descritas acima.

Na dimensão Presença foi constatado que as empresas não criaram nenhum ponto ou canal de venda diferente dos existentes anteriormente, assim como não estabeleceram novas relações com distribuidores para a venda dos seus produtos e serviços. Os dados demonstram que as empresas não buscam entrar em novos mercados, nem atender a outro público-alvo, ficando restrita a sua venda de produtos ao seu ponto comercial.

Na dimensão Ambiência Inovadora constatou-se que grande parte das empresas analisadas não fizeram uso de consultorias ou do apoio de entidades como o SEBRAE, SENAI, SESI, universidades, empresas júnior, sindicatos patronais ou serviços como o Serviço de Respostas Técnicas - SBRT.

A empresa com um maior grau de inovação é a $\mathrm{G}$, a pontuação 3,2 evidencia e comprova os investimentos e mudanças que a empresa fez durante os três últimos anos. Aquisição de novos equipamentos, registro de marca, oferta de novos produtos e serviços aos clientes são algumas das ações implantadas por essa empresa que possui um ambiente propicio a inovação.

Em seguida, destacam-se as empresas B e D, que, assim como a $\mathrm{G}$, investiram em novas mudanças. As duas empresas citadas têm um tempo de mercado significativo e muita experiência no setor em que atuam. Estão sempre buscando novos conhecimentos para aplicar no negócio. A empresa D oferece ao cliente um mix de serviços diferenciado. Já a B é especializada em convites e referência no mercado.

Já as empresas A e E possuem os graus de inovação praticamente iguais: 2,1 e 2,0, respectivamente. Os gestores entrevistados estão começando a investir nas empresas, adquirindo maquinário para expandir seu mix de produtos e serviços, fazendo mudanças em seus layouts, logomarcas e nos itens que compõem a marca, entre outras ações que possibilitarão o desenvolvimento e expansão das empresas.

As empresas $\mathrm{Ce} \mathrm{F}$ foram as que menos implantaram mudanças organizacionais. Os gestores entrevistados afirmaram que a ausência de capital não permitiu que as ações planejadas fossem cumpridas.

\section{Análise da dimensão Relacionamento}

A dimensão Relacionamento, nos três últimos anos de atividade, não foi desenvolvida por grande parte das empresas. Não foi prioridade o investimento em novos recursos e facilidades que pudessem agregar valor e manter o cliente satisfeito com a empresa.

Os critérios que compõem a dimensão Relacionamento do Radar da Inovação preocupam os gestores, pois, com a competitividade acirrada, o que propicia preços competitivos no mercado, se torna mais difícil fidelizar os clientes. Investimentos em websites, brindes em datas comemorativas, salas personalizadas e visitas externas já estão sendo avaliados com um grau de importância maior pelos gestores, tendo em vista a preocupação do segmento em manter um relacionamento duradouro com o cliente.

Os resultados das entrevistas permitiram identificar e analisar a dimensão comos gestores das sete gráficas de micro e pequeno porte. Mediante análise estatística, por meio da aplicação do questionário, obtiveram-se os resultados que serão expostos em conseguinte. 
Tabela 6 - Ações de marketing de relacionamento.

\begin{tabular}{|c|c|c|c|c|c|}
\hline $\begin{array}{l}\text { A empresa nos } \\
\text { últimos anos } \\
\text { adotou facilidades } \\
\text { ou recursos para } \\
\text { melhoria do } \\
\text { relacionamento } \\
\text { com os clientes, } \\
\text { tais como: }\end{array}$ & $\begin{array}{c}\text { Cartão de } \\
\text { aniversário }\end{array}$ & Brindes & $\begin{array}{c}\text { Sala de } \\
\text { espera }\end{array}$ & Cafezinho & $\begin{array}{l}\text { Atendimento } \\
\text { personalizado }\end{array}$ \\
\hline \multirow{3}{*}{$\begin{array}{l}\text { Dentre os canais } \\
\text { de comunicação } \\
\text { abaixo, a empresa } \\
\text { utiliza para se } \\
\text { relacionar com } \\
\text { seus clientes: }\end{array}$} & $0 \%$ & $33 \%$ & $17 \%$ & $17 \%$ & $33 \%$ \\
\hline & Telefone & Site & Email & Facebook & $\begin{array}{c}\text { Visitas } \\
\text { externas }\end{array}$ \\
\hline & $30 \%$ & $15 \%$ & $35 \%$ & $5 \%$ & $15 \%$ \\
\hline
\end{tabular}

Fonte: Pesquisa de campo (2012).

A Tabela 6 corresponde às facilidades ou recursos utilizados pela empresa, para aperfeiçoar e melhorar o relacionamento com seus clientes, assim como os canais de comunicação usados pelos empresários. Das opções sugeridas foi possível constatar que $33 \%$ das empresas utilizam o atendimento personalizado e brindes como recursos que tenham como intuito promover uma maior satisfação por parte dos clientes. Do total, $17 \%$ utiliza salas de espera e cafezinho, um resultado inexpressivo, tendo em vista a importância de manter o cliente confortável no ambiente enquanto ele aguarda o atendimento. Esse resultado é contraditório à teoria de Almeida (2002), segundo a qual fidelizar o cliente é a chave para a lucratividade e o crescimento da empresa. Atrair o cliente não basta mais, mantê-lo se tornou mais importante.

O e-mail é o canal mais eficaz citado: $35 \%$ das empresas aproveitam esse meio para enviar informações importantes ao cliente, como orçamentos, promoções, divulgação dos produtos e serviços, entre outras. O telefone corresponde a $30 \%$ no grau de importância desses gestores.

As demais opções são importantes para qualquer organização, porém não são utilizadas de forma dinâmica pelos empresários, o que traria bons resultados em termos de divulgação e ampliação do cadastro de clientes. O website, pouco utilizado pelas empresas analisadas, é uma ferramenta rápida e eficiente de comunicação: através dela o cliente pode conhecer a história da empresa, visualizar os serviços que ela oferece por meio de um portfólio próprio, solicitar orçamentos, recrutar e selecionar pessoas pelo link "envie seu currículo", entre outras opções que aperfeiçoariam os processos de relacionamento das empresas com seus clientes. 
Tabela 7 -Ações de marketing de relacionamento.

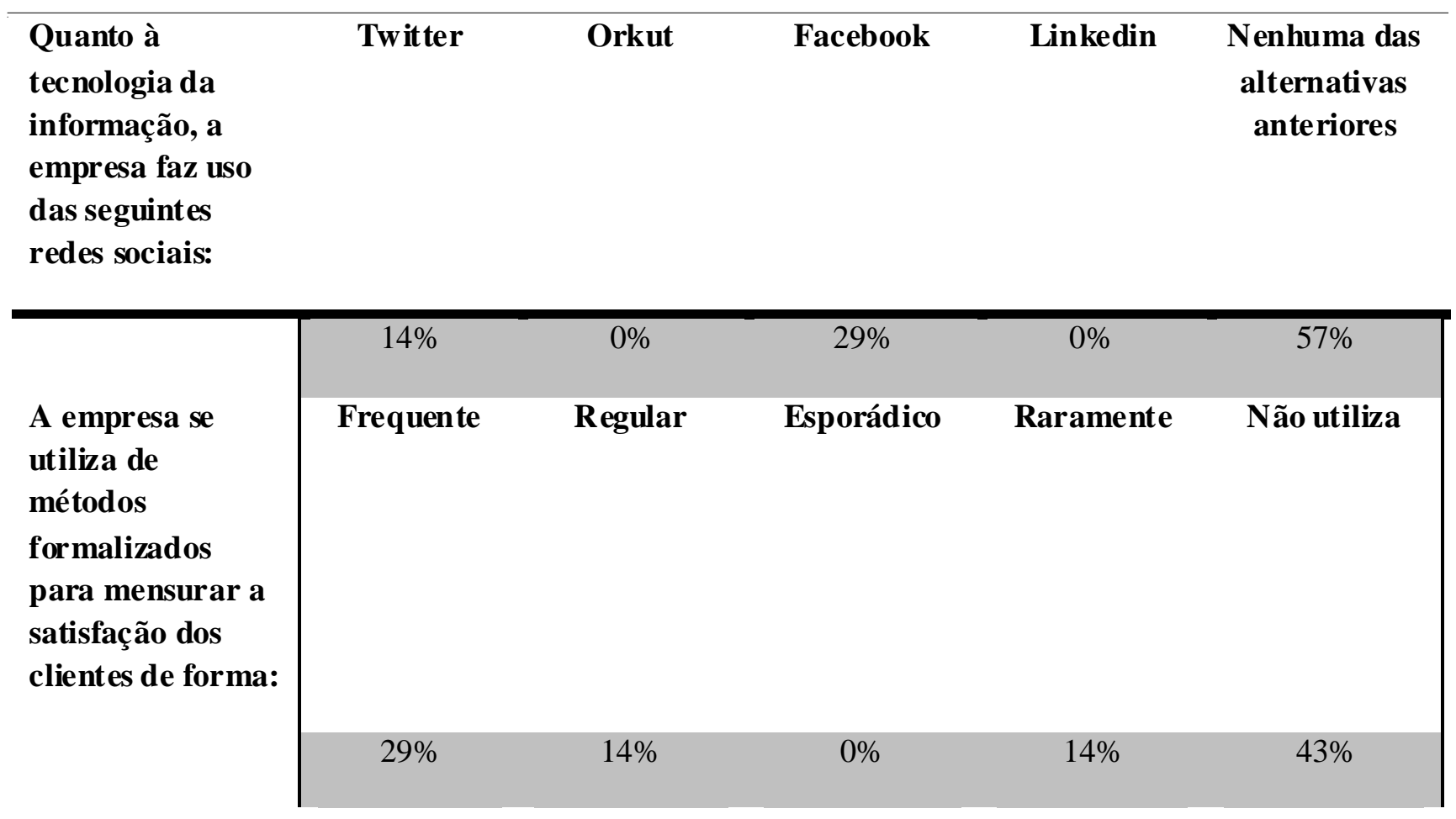

Fonte: Pesquisa de campo (2012)

A Tabela 7 verifica o uso da tecnologia da informação como forma de diferenciação no relacionamento com os clientes. Entretanto, foi constatado que $57 \%$ das empresas não estão nas redes sociais. Apenas 29\% utilizam o Facebook e 14\%, o Twitter. Como avanço da tecnologia da informação e dos meios de comunicação, o uso das redes sociais no mundo corporativo vem aumentando ao longo dos anos. É cada vez maior o número de empresas que estão aderindo. Por meio do Facebook e o Twitter, por exemplo, a divulgação pode ser realizada através de fotos no mural, além de manter o cliente atualizado quanto às novidades e informações da empresa. No segmento gráfico estudado, a utilização das redes sociais ainda é pouco significativo, grande parte das empresas não utilizam esses meios de comunicação.

O pós-venda é uma ferramenta primordial de pesquisa, pois ajuda a compreender e mensurar a satisfação dos clientes com a empresa, por meio de informações que permitirão correções no processo de venda. A Tabela 7 faz referência à utilização de métodos formalizados para mensurar a satisfação do cliente com a empresa, como uma avaliação de satisfação anual ou periódica - $43 \%$ dos gestores não fazem uso desses métodos para conhecer a satisfação dos clientes com os produtos e serviços que a eles são ofertados. As demais empresas fazem uso frequente, regular ou raramente utilizam o método. O pós-venda não é uma prática muito utilizada pelas empresas pesquisadas, sendo assim, grande parte delas não conhece os graus diversos de opinião e satisfação dos clientes. Para Bentes (2012, p.153) muitas empresas perdem seus clientes por problema de atendimento no pós-venda. 
Tabela 8 - Ações de marketing de relacionamento.

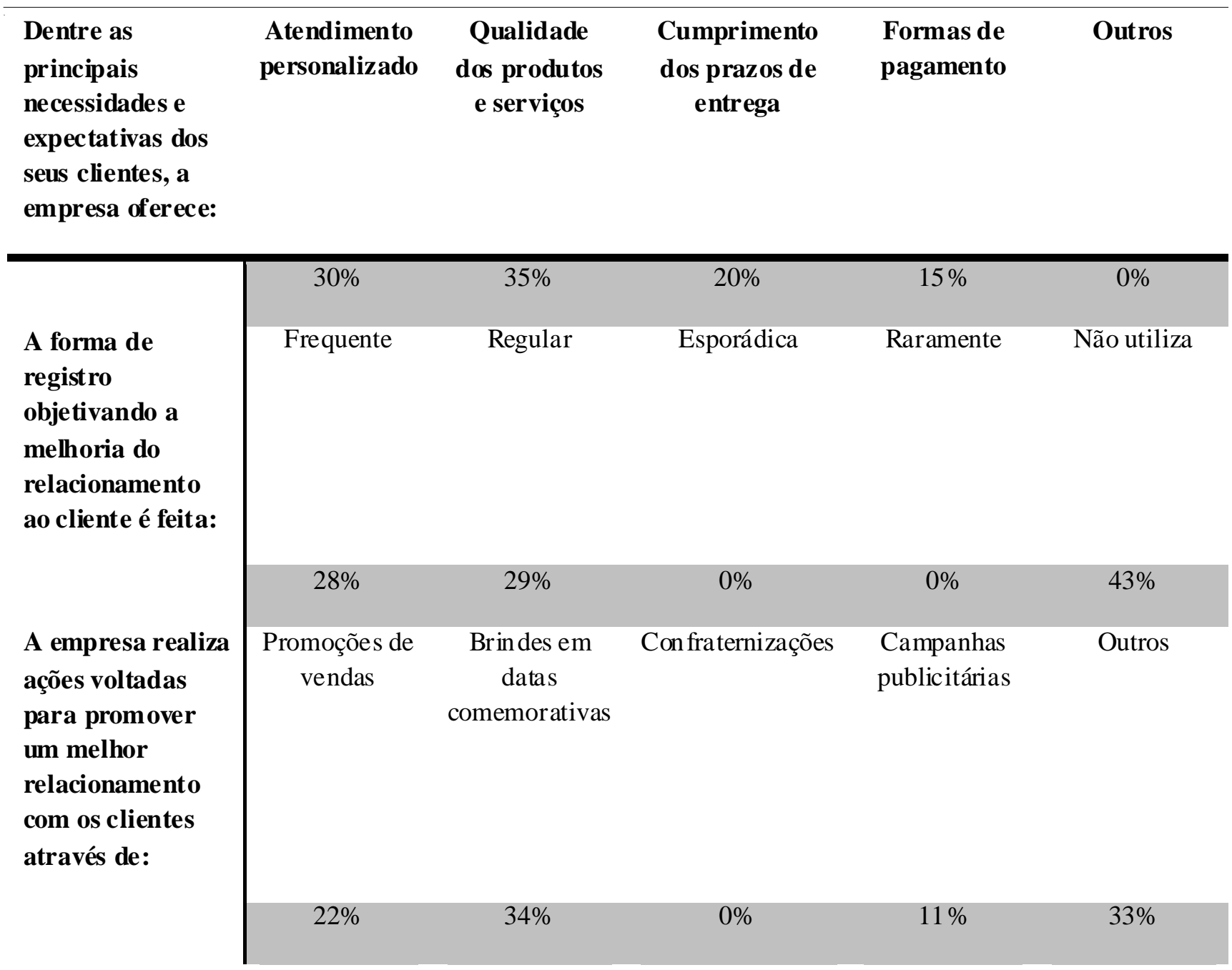

Fonte: Pesquisa de campo (2012).

As organizações devem conhecer antecipadamente os desejos e expectativas dos clientes. Isso pode ser feito por meio de perguntas abertas para que os clientes possam repassar com clareza essas informações, de visitas indicando interesse nas relações, de parcerias, entre outras ações que propiciem reconhecer o que os clientes esperam e desejam dos produtos e serviços oferecidos. A Tabela 8 apresenta as opções que a empresa oferece, tendo em vista o conhecimento das principais necessidades e expectativas dos clientes. Qualidade dos produtos e serviços é a opção que elas mais valorizam e cumprem no atendimento aos seus clientes. Atendimento personalizado e cumprimento dos prazos de entrega se tornam fatores importantes para a satisfação do consumidor, com $30 \%$ e $20 \%$, respectivamente. Os dados coletados condizem com a afirmação de Bentes (2012, p. 61) que o caminho para o sucesso é entender as necessidades e expectativas dos clientes, para que junto venham argumentos e possibilidade de venda e bom atendimento após a compra do produto ou serviço. 
Na Tabela 8 pode-se constatar como é feita a forma de registro objetivando a melhoria do relacionamento com o cliente, como as reclamações e as sugestões, por exemplo - $43 \%$ dos entrevistados não utilizam nenhum meio de registro formalizado. É importante conhecer os clientes, saber como eles pensam, como decidem e do que gostam e não gostam. Por esses motivos são bem-vindas as pesquisas de opinião formais. Com essas informações, a empresa evita a insatisfação do cliente, resolvendo seu problema de imediato e registrando para que ele não se repita novamente. Dentre as empresas pesquisadas, $29 \%$ fazem isso de forma regular e $28 \%$, frequentemente, percentuais ainda pequenos, tendo em vista a importância dessa prática.

Atualmente é importante a empresa realizar ações que sejam direcionadas aos seus clientes, como forma de diferenciação, em razão da concorrência acirrada, principalmente no segmento pesquisado. Na Tabela 8 podem ser visualizadas as ações para promover um melhor relacionamento com os clientes: $34 \%$ das empresas enviam brindes em datas comemorativas, em sua maioria no Natal e ano-novo. No segmento gráfico, os brindes são geralmente os itens mais enviados aos clientes: agendas, canetas, calendários e canecas fazem parte das opções personalizadas mais utilizadas. Observa-se que apenas $11 \%$ se envolvem em campanhas publicitárias, tendo em vista a importância de firmar parcerias de longo prazo, 22\% possuem promoções de vendas e não há confraternizações com os clientes.

De acordo com a análise apresentada, foi possível perceber que as empresas representadas por seus gestores precisam adotar práticas que visem aumentar o relacionamento com seus clientes, por meio de ações voltadas para um bom atendimento, conhecer suas necessidades e expectativas, estabelecer meios de comunicação mais eficientes e formalizar seus processos. Essas ações irão propiciar que o cliente enxergue a empresa de um modo diferenciado e não a procure apenas por ela ter o preço mais competitivo em relação as suas concorrentes.

\section{Considerações finais}

Conforme foi observado, o segmento gráfico está sempre em constantes mudanças; portanto, se faz necessário que as empresas absorvam a cultura da inovação para se diferenciar e conquistar lugar no mercado em que atuam. Algumas das empresas investem em equipamentos modernos, entretanto, em sua maioria, colocam a questão do relacionamento com o cliente em segundo plano.

O presente artigo se propôs a analisar como o segmento gráfico do município de Natal utiliza o marketing de relacionamento para conquistar e fidelizar clientes. Os dados permitem confirmar que as organizações investigadas precisam de ajustes e conhecimentos no que diz respeito à importância do relacionamento com os clientes como estratégia competitiva de mercado.

É possível compreender que parte das empresas, fontes de pesquisa para a realização do paper, conhece as necessidades e desejos dos seus clientes; contudo, atender com excelência o cliente não é a prioridade principal. Algumas ações são realizadas, porém esse número não é significativo. Praticar um preço mais competitivo em relação à concorrência na indústria gráfica é o fator primordial na conquista dos clientes, tendo em vista que a qualidade, os prazos de entrega, as formas de pagamentos são praticamente iguais em todas as empresas do segmento.

A pesquisa mostrou a falta de interesse dos empresários no investimento em capacitações para seus colaboradores, o que muitas vezes pode ser prejudicial no contato direto, já que não possuem conhecimentos adequados para lidar e atender os clientes de maneira apropriada.

Alguns dos gestores, preocupados com as mudanças ocorridas no setor, estão visualizando a importância de adotar facilidades ou recursos que venham a melhorar o relacionamento com seus clientes, criando novos canais de comunicação e divulgação dos seus produtos e serviços. Os sites e as redes sociais são meios importantes nesse processo de estruturação de uma comunicação mais rápida e eficiente. 
A pesquisa foi limitada às indústrias gráficas atendidas pelo Programa ALI, e o estudo mostrou que, dentro do que já foi citado e de acordo com o que foi observado, seriam necessários, inicialmente, a realização de uma pesquisa de mercado e perfil do cliente, o aumento da capacidade gerencial do responsável, por meio de capacitações, e o desenvolvimento da visão da importância do marketing de relacionamento para a sobrevivência de toda e qualquer organização. Para o gestor, essa prática pode ser feita através de ações inovadoras que tragam benefícios para a empresa, como a aproximação do cliente.

Quanto à pesquisa, pode-se evidenciar que o universo de gráficas no município de Natal é muito extenso, e a pesquisa poderia ser expandida para todo o setor; assim, poderia ser feita uma comparação entre as empresas com informações precisas e completas.

\section{REFERÊNCIAS}

ALMEIDA, Sergio. Ah! Não acredito. São Paulo: Casa da Qualidade, 2002.

BACHMANN, Dórian L. e DESTEFANI, JullyHeverly. Metodologia para estimar o grau de inovação nas MPE: cultura do empreendedorismo e inovação. Curitiba, 2008.

BEE, Frances; BEE Roland. Fidelização do cliente. São Paulo: Nobel, 2000.

BENTES, Otávio. Atendimento ao cliente. Curitiba: IESDE, 2012.

BESSANT, J.; TIDD, J. Inovação e empreendedorismo. Porto Alegre: Bookman, 2009.

BRITO, K. N.; CANDIDO, G. A. Difusão da Inovação Tecnológica como mecanismo de contribuição para a formação de diferenciais competitivos em pequenas e médias empresas.

READ, Porto Alegre, v. 9, n. 2, Abril 2003.

DALRYMPLE, Douglas J; PARSONS, Leonard J. Introdução à administração de marketing. 2. ed. Rio de Janeiro: LTC, 2003.

FELISONI, C.A; GIAGRANDE, V. Marketing de relacionamento no varejo. São Paulo: Saint Paul, 2007.

GUMMESSON, Evert. Marketing de relacionamento total. 3.ed. Porto Alegre: Bookman. 2010.

KOTLER, Philip; KELLER, Kevin Lane. Administração de marketing. 12. ed. São Paulo: Pearson Prentice Hall, 2006.

KOTLER, Philip. Administração de marketing. 10. ed. São Paulo: Novo Milênio, 2000.

MADRUGA, Roberto. Guia de Implementação do marketing de relacionamento e CRM. São Paulo: Atlas, 2006.

MALHOTRA, Naresh K. etall. trad.Robert Brian Taylor. Introdução à pesquisa de marketing. São Paulo: Pearson Prentice Hall, 2005.

OCDE. Manual de Oslo: Proposta de Diretrizes para coleta e interpretação de dados sobre inovação. 3. ed. Tradução FINEP, 2004, disponível em www.finep.org.br. Acesso em: 26 ago. 2012.

\section{SARKAR, Soumodip. O empreendedor} inovador: faça diferente e conquiste seu espaço no mercado. Rio de Janeiro: Elsevier, 2008.

SEBRAE. Agentes locais de inovação: Uma medida do progresso nas MPEs do Paraná. 
Curitiba, 2010.

SEBRAE. Guia para inovação na micro e pequena empresa. Curitiba, 2009.

SINGRAF-Sindicato das Indústrias Gráficas do Rio Grande do Norte. O setor gráfico do Rio Grande do Norte. Natal, 2011.
VERGARA, Sylvia Constant. Métodos de pesquisa em administração. São Paulo: Atlas, 2005.

VERGARA, Sylvia Constant. Projetos e relatórios de pesquisa em administração. 8. ed. São Paulo: Atlas, 2007. 